\title{
Penerapan Metode Instalasi Tangki Cryogenic Di Rumah Sakit Untuk Mewujudkan Konsep Green Economic Dalam Bentuk Green Logistic (Studi Kasus di PT. Sentosa Ultra Gasindo)
}

\author{
La Ode Sabaruddin a,1,* \\ ${ }^{a}$ Institut Ilmu Sosial dan Manajemen STIAMI \\ ${ }^{1}$ Laoderudi79@gmail.com* \\ * corresponding author
}

\section{ARTICLE INFO}

\section{Article history}

Received Desember 2019

Revised Januari 2020

Accepted Februari 2020

\section{Keywords}

Green Economic,

Green Logistics,

Cryogenic,

Efficiency,

Effectiveness

\begin{abstract}
The embodiment of green economy is increasingly sought by various companies throughout the world. This is done as a form of responsibility and care to help preserve nature and maintain the survival of living things in it.

PT. Sentosa Ultra Grasindo as one of the companies engaged in the gas industry that provides various types of gas, one of which is medical gas applying the cryogenic tank installation method to help realize the green economy. This study aims to determine how the impact of the application of Cryogenic Tank installation methods in hospitals to the realization of green economy in the form of green logistics for oxygen distribution activities to XYZ Hospital, which is its client.

This is a qualitative descriptive study using primary data types obtained from in-depth interviews and observations of related parties. The results showed that the method of installing cryogenic tanks in hospitals was considered to be more environmentally friendly and realize effectiveness and efficiency for PT. Sentosa Ultra Gasindo and for XYZ Hospital.
\end{abstract}

\section{PENDAHULUAN}

Bumi sebagai tempat tinggal bagi seluruh makhluk hidup yang mendiaminya sangat penting untuk dijaga kelestariannya. Tidak sedikit kerusakan alam yang terjadi yang diakibatkan oleh berbagai hal antara lain polusi udara yang disebabkan oleh asap kendaraan bermotor, polusi air yang dikarenakan oleh limbah yang berasal dari pabrik, pemanasan global akibat penebangan hutan secara liar, dan lain-lain. Permasalahan tersebut sudah sepantasnya menjadi perhatian serius dan harus ditemukaan solusinya demi terjaganya keberlangsungan hidup.

Dewasa ini, perusahaan dari berbagai belahan dunia terus melakukan inovasi-inovasi demi terwujudnya green economic dalam aktifitas perusahaan mereka. Hal tersebut dilakukan untuk ikut menjaga kelestarian alam dan seluruh makhluk hidup yang berada di dalamnya. Dikutip dari Wikipedia, green economic diartikan sebagai kegiatan ekonomi yang bertujuan untuk mewujudkan pengurangan risiko lingkungan dan kelangkaan ekologis, dan bertujuan untuk pembangunan berkelanjutan tanpa merusak lingkungan.

PT. Sentosa Ultra Gasindo adalah salah satu distributor dan Filling Station Gas Medic, gas industri dan rumah tangga yang juga bergerak di bidang pengadaan Instalasi Gas Medis, Industri, Laboratorium dan Tambang, Purging, Flushing Tangki N2, Piping Gas dan Tangki. Partisipasinya dalam hal berusaha mewujudkan green economic sebagai bentuk kepeduliannya untuk ikut menjaga kelestarian alam diwujudkan PT. Sentosa Ultra Gasindo dengan melakukan green logistic salah satunya dalam aktifitas distribusi oksigen ke rumah sakit yang menjadi klien mereka dengan melakukan perubahan yang sebelumnya oksigen disuplai dalam bentuk kemasan tabung yang dikirimkan berdasarkan pesanan dari rumah sakit, kini beralih dengan melakukan instalasi tangki cryogenic di rumah sakit sehingga pengiriman oksigen selanjutnya hanya dalam bentuk liquid untuk kemudian dimasukan ke dalam tangki yang sudah diinstal di rumah sakit. 
Selain dinilai lebih ramah lingkungan, pengiriman oksigen dalam bentuk liquid tidak membutuhkan jumlah truk pengangkut yang banyak dan volume yang besar yang hubungannya bisa berdampak pada penggunaan bahan bakar yang lebih banyak, metode instalasi tangki cryogenic juga berdampak pada terjaganya stok persediaan oksigen di rumah sakit yang menjadi klien PT. Sentosa Ultra Gasindo yang mana sebelumnya sering mengalami kehabisan stok yang dikarenakan pengiriman yang terlambat akibat beberapa faktor seperti kemacetan atau pemesanan yang terlambat.

Berdasarkan latar belakang tersebut, maka penulis tertarik untuk membuat penelitian dengan judul "Penerapan Metode Instalasi Tangki Cryogenic Di Rumah Sakit Untuk Mewujudkan Konsep Green Economic Dalam Bentuk Green Logistic (Studi Kasus di PT. Sentosa Ultra Gasindo).”

\section{TINJAUAN PUSTAKA}

\section{Green Economic}

Menurut Wikipedia (2019) Green Economic (ekonomi hijau) didefinisikan sebagai kegiatan ekonomi yang bertujuan untuk mewujudkan pengurangan risiko lingkungan dan kelangkaan ekologis, dan yang bertujuan untuk pembangunan berkelanjutan tanpa merusak lingkungan. Sedangkan menurut UNEP (United Nations Environment Programme) (2010), green economic adalah sistem yang memuat semua aktifitas perekonomian (produksi, distribusi, dan konsumsi), yang menghasilkan peningkatan kulaitas hidup manusia untuk jangka panjang, tanpa mengorbankan kepentingan generasi mendatang akibat munculnya risiko terkait dampak lingkungan dan keterbatasan ekosistem.

\section{Green Logistic}

Dikutip dari swa.co.id, Martono (2017), mendefinisikan Green Logistics sebagai konsep logistik mulai dari proses pengolahan barang hingga konsumen dapat menggunakan barang tersebut, dengan penekanan tidak merusak lingkungan dan menggunakan sebanyak mungkin bahan mentah yang ramah lingkungan. Setelah pemakaian, barang dikirim kembali dari konsumen kepada produsen untuk diperbaiki atau diolah menjadi barang yang tetap ramah lingkungan (recycle).

Berdasarkan definisi tersebut secara sederhana, green logistic adalah suatu bentuk logistik yang memperhitungkan aspek sosial dan ramah lingkungan disamping aspek fungsional dan ekonomis.

\section{Instalasi}

Menurut Kamus Besar Bahasa Indonesia, instalasi adalah perangkat peralatan teknik beserta perlengkapannya yang dipasang pada posisinya dan siap dipergunakan. Sedangkan menurut Wikipedia (2019), installation adalah adalah seni yang memasang, menyatukan, dan mengkontruksi sejumlah benda yang dianggap bisa merujuk pada suatu konteks kesadaran makna tertentu.

Berdasarkan keedua definisi di atas dapat disimpulkan bahwa instalasi adalah seni memasang dan menyatukan sebuah alat di suatu tempat untuk siap dipergunakan.

\section{Tangki Cryogenic}

Menurut menurut Wikipedia (2016), cryogenic adalah ilmu yang mempelajari materi dengan temperatur sangat rendah (di bawah $-150{ }^{\circ} \mathrm{C},-238^{\circ} \mathrm{F}$ atau $123 \mathrm{~K}$ ). Ilmu ini mempelajari cara memproduksi serta perilaku material pada temperatur tersebut.

Menurut Yunita (2012), Cryogenic merupakan metode pembekuan yang menggunakan gas yang dimanfaatkan menjadi cairan (liquid) misalnya nitrogen (N2) dan karbon dioksida (Co2). Nitrogen cair sebagaimana telah diketahui sejak lama, dipergunakan sebagai pembeku bahan-bahan organik untuk keperluan penyimpanan dan ekstraksibahan-bahan penelitian bidang biologi terapan. Karbon dioksidacair pun telah sejak lama dipergunakan untuk pengisi tabung pemadam kebakaran.

Sehubungan dengan penelitian ini, berdasarkan definisi di atas, maka dapat diambil kesimpulan bahwa tangki cryogenic untuk supply oksigen di rumah sakit adalah tangki untuk menyimpan liquid yang kemudian akan dikonversi menjadi oksigen dan disalurkan melalui pipa ke kamar-kamar rumah sakit.

\section{Efisiensi}

Menurut Hasibuan (2005), efisiensi adalah perbandingan yang terbaik antara input (masukan) dan 
output (hasil antara keuntungan dengan sumber-sumber yang dipergunakan), seperti halnya juga hasil optimal yang dicapai dengan penggunaan sumber yang terbatas. Dengan kata lain hubungan antara apa yang telah diselesaikan.

Sedangkan menurut Kamus Besar Bahasa Indonesia (2016), menyatakan bahwa efisiensi adalah ketepatan cara (usaha, kerja) dalam menjalankan sesuatu (dengan tidak membuang waktu, tenaga, biaya), kedayagunaan, ketepatgunaan, kesangkilan serta kemampuan menjalankan tugas dengan baik dan tepat (dengan tidak membuang waktu, tenaga, biaya).

Berdasarkan kedua definisi tersebut, dapat disimpulkan bahwa efisiensi adalah bagaimana menjalankan sesuai agar didapatkan hasil yang optimal serta menghindari pemborosan dalam segi waktu, tenaga dan biaya.

\section{Efektifitas}

Menurut Masruri (2014), Efektivitas adalah seberapa baik pekerjaan yang dilakukan, sejauh mana orang menghasilkan keluaran sesuai dengan yang diharapkan. Ini berarti bahwa apabila suatu pekerjaan dapat diselesaikan dengan perencanaan, baik dalam waktu, biaya maupun mutunya, maka dapat dikatakan efektif.

Sedangkan menurut Gibson et.al dalam Bungkaes (2013), efektivitas adalah penilaian yang dibuat sehubungan dengan prestasi individu, kelompok, dan organisasi. Makin dekat prestasi mereka terhadap prestasi yang diharapkan (standar), maka makin lebih efektif dalam menilai mereka.

Berdasarkan pengertian tersebut dapat disimpulkan bahwa efektivitas adalah pencapaian sebuah keluaran atau hasil yang dilakukan dengan cara yang baik dalam hal waktu, biaya, dan mutunya oleh individu, kelompok ataupun sebuah organisasi.

\section{Penelitian Terdahulu}

Metode instalasi tangki cryogenic di rumah sakit adalah metode penyimpanan liquid oksigen ke dalam tangki untuk kemudian disalurkan ke kamar-kamar rumah sakit melalui pipa.

Senada dengan itu, sebuah penelitian yang dilakukan oleh Wiguna (2014) yang meneliti terkait tangki penyimpanan LNG On-Shore menyatakan dalam penelitiannya sebagai berikut : "Dalam industri energi khususnya bidang LNG, tangki penyimpanan merupakan suatu hal yang vital dan sangat penting, karena disinilah letak tujuan dari pencairan gas. Pencairan gas ditujukan agar penyimpanan dari gas alam menjadi lebih mampat 600 kalinya dari fase gasnya, sehingga lebih ekonomis jika disimpan atau di transportasikan. Begitu juga dengan industri lainnya, tangki penyimpanan juga bervariasi sesuai dengan klasifikasinya."

Dari pernyataan tersebut terlihat bahwa metode instalasi tangki untuk penyimpanan gas dinilai lebih memberikan manfaat secara ekonomis. Selain itu juga, dalam penelitiannya Wiguna menyatakan bahwa berbagai jenis tangki penyimpanan akan selalu didesain agar dapat menahan kebocoran liquid dan juga dapat menahan uap gas alam tidak lepas ke lingkungan sehingga lebih ramah terhadap lingkungan.

Suyanto (2014) menyatakan bahwa keunggulan pembekuan dengan metode cryogenic antara lain ; peralatan yang relatif ringkas dan dapat beroperasi secara kontinyu sehingga biaya modal relatif rendah (sekitar 30\% dari biaya modal pembekuan mekanik) dan konsumsi energi lebih rendah sehingga lebih ramah terhadap lingkungan.

\section{METODE PENELITIAN}

\section{Desain Penelitian}

Penelitian ini dilakukan dengan tujuan untuk mengetahui bagaimana dampak dari dilakukannya perubahan proses distribusi oksigen oleh PT. Sentosa Ultra Gasiondo yang sebelumnya oksigen dikirim dalam kemasan tabung setiap kali ada permintaaan dari rumah sakit dan kini diganti dengan penginstalan tangki cryogenic di rumah sakit sehingga oksigen dikirim hanya dalam bentuk liquid. Penelitian dilakukan dengan menggunakan metode penelitian kualitatif.

Bogdan dan Taylor dalam Maloeng (2012) mendefinisikan metodologi kualitatif sebagai prosedur penelitian yang menghasilkan data deskriptif berupa kata-kata tertulis atau lisan dari orang-orang dan 
perilaku yang dapat diamati. Sedangkan menurut Menurut Sugiyono (2012) metode penelitian kualitatif adalah metode penelitian yang di gunakan untuk meneliti pada kondisi objek yang alamiah, dimana peneliti adalah instrumen kunci, teknik pengumpulan data dilakukan secara triangulasi (gabungan), analisis data bersifat induktif dimana hasil penelitian lebih menekankan makna dari pada generalisasi.

\section{Pengumpulan Data}

Teknik pengumpulan data yang dilakukan dalam penelitian kualititatif ini ini yaitu :

\section{a. Data Primer}

Menurut Sugiyono (2010) data primer adalah sumber data yang langsung memberikan data kepada pengumpul data. Pengumpulan data primer dalam penelitian ini melalui cara menyebarkan kuesioner dan melakukan wawancara secara langsung dengan pihak-pihak yang berhubungan dengan penelitian yang dilakukan, dalam hal ini auditor eksternal.

Data diperoleh dari wawancara mendalam untuk mendapatkan informasi dari responden yang telah dipilih berdasarkan pengetahuan dan kemampuan yang dimiliki sehubungan dengan permasalahan yang sedang diteliti. Wawancara mendalam dalam penelitian ini digunakan untuk mencari informasi terkait perubahan-perubahan yang terjadi dalam berbagai hal baik itu efisiensi, efektifitas, dan terutama pengaruh perubahan metode distribusi oksigen ke tangki cryogenic hubungannya dengan perwujudan green logistic yang dicanangkan PT. Sentosa Ultra Gasiondo.

b. Data Sekunder

Menurut Sugiyono (2010:137), data sekunder adalah sumber yang tidak langsung memberikan data kepada pengumpul data, misalnya lewat orang lain atau lewat dokumen.

Data sekunder diperoleh dari telah dokumen PT. Sentosa Ultra Gasindo, yaitu invoice terkait pembayaran instalasi tangki, pembayaran sewa tangki, serta volume dan harga pemesananan liquid oleh pihak rumah sakit.

\section{Validasi Data}

Dalam melakukan pemeriksaan keabsahan data dalam penelitian kualitatif dilakukan dengan menggunakan metode triangulasi. Denzin (2009), mendefinisikan triangulasi sebagai gabungan atau kombinasi berbagai metode yang dipakai untuk mengkaji fenomena yang saling terkait dari sudut pandang dan perspektif yang berbeda.

Menurut Sugiyono (2012), dalam teknik pengumpulan data, triangulasi diartikan sebagai teknik pengumpulan data yang bersifat menggabungkan dari berbagai teknik pengumpulan data dan sumber data yang telah ada. Bila peneliti melakukan pengumpulan data dengan triangulasi, maka sebenarnya peneliti mengumpulkan data yang sekaligus menguji kredebilitas data, yaitu mengecek kredibilitas data dengan berbagai teknik pengumpulan data dan berbagai sumber data.

Triangulasi yang dilakukan dalam penelitian ini, yaitu :

\section{Triangulasi Sumber}

Menurut Sugiyono (2010), triangulasi sumber untuk menguji kredibilitas data dilakukan dengan cara mengecek data yang telah diperoleh melalui beberapa sumber.

Dalam penelitian ini, triangulasi sumber dilakukan dengan membandingkan dan melakukan pemeriksaan terhadap hasil wawancara dengan menanyakan pertanyaan yang sama kepada beberapa sumber dengan jabatan yang berbeda namun masih dalam satu rangkaian pekerjaan yang sama di PT. Sentosa Ultra Gasindo. 
Tabel 3.1

Triangulasi Sumber

\begin{tabular}{|c|c|c|c|c|}
\hline & R-1 & R-2 & R-3 & R-4 \\
\hline \multicolumn{5}{|l|}{ INPUT } \\
\hline Distribusi & $\sqrt{ }$ & $\sqrt{ }$ & & $\sqrt{ }$ \\
\hline Biaya & $\sqrt{ }$ & & & $\sqrt{ }$ \\
\hline \multicolumn{5}{|l|}{ OUTPUT } \\
\hline Perwujudan Green Logistic & $\sqrt{ }$ & & & $\sqrt{ }$ \\
\hline Efisiensi & $\sqrt{ }$ & $\sqrt{ }$ & & $\sqrt{ }$ \\
\hline Efektifitas & $\sqrt{ }$ & $\sqrt{ }$ & & \\
\hline
\end{tabular}

Sumber : Peneliti (2019)

Keterangan :

$\mathrm{R}=$ Responden

R-1 = Kepala Filling Station PT Sentosa Ultra Gasindo

R-2 = Wakil Kepala Filling Station PT Sentosa Ultra Gasindo

R-3 = Staff Filling Station PT. Sentosa Ultra Gasindo

R-4 = Distributor (Bagian Pengiriman)

2. Triangulasi Metode

Menurut Sugiyono (2012), Triangulasi metode artinya peneliti menggunakan metode pengumpulan data yang berbeda-beda untuk mendapatkan data dari sumber yang sama. Triangulasi metode dalam penelitian ini dilakukan dengan wawancara, observasi, dan telaah dokumen.

Tabel 3.2

Triangulasi Metode

\begin{tabular}{|l|c|c|c|}
\hline & $\begin{array}{c}\text { Wawancara } \\
\text { Mendalam }\end{array}$ & Observasi & $\begin{array}{c}\text { Telaah } \\
\text { Dokumen }\end{array}$ \\
\hline INPUT & $\sqrt{|c|}$ \\
\hline Distribusi & $\sqrt{ }$ & $\sqrt{ }$ & $\sqrt{ }$ \\
\hline Biaya & $\sqrt{ }$ & $\sqrt{ }$ & \\
\hline OUTPUT & $\sqrt{ }$ & & $\sqrt{ }$ \\
\hline Perwujudan Green Logistic & $\sqrt{ }$ & $\sqrt{ }$ & \\
\hline Efisiensi & $\sqrt{\mid}$
\end{tabular}

Sumber : Peneliti (2019)

Tujuan dilakukannya validasi data dengan mengambil dari sumber yang berbeda dan metode yang beragam adalah agar didapatkan hasil analisis yang tepat, akurat, dan dapat dipercaya.

\section{HASIL DAN PEMBAHASAN}

\section{Gambaran Umum PT. Sentosa Ultra Gasindo}

PT. Sentosa Ultra Gasiondo berdiri tahun 2012 dan berdomisili di Cikarang Baru, Kabupaten Bekasi dan menjadi distributor dari PT. Air Produk yang merupakan Pabrik Gas Multi Nasional untuk gas medis dan industri. PT. Sentosa Ultra Gasindo merupakan distributor dan Filling Station Gas Medis dan bergerak juga di bidang pengadaan instalasi gas medis, industri, piping gas dan tangki.

Berikut adalah data instalasi dan pemesanan liquid oksigen dari PT. Sentosa Ultra Gasindo pada salah satu rumah sakit yang menjadi kliennya (untuk selanjutnya akan disebut Rumah Sakit XYZ). 
Tabel 4.1

Data Instalasi tangki Cryogenic dan Pemesanan Liquid di PT. Sentosa Ultra Gasindo

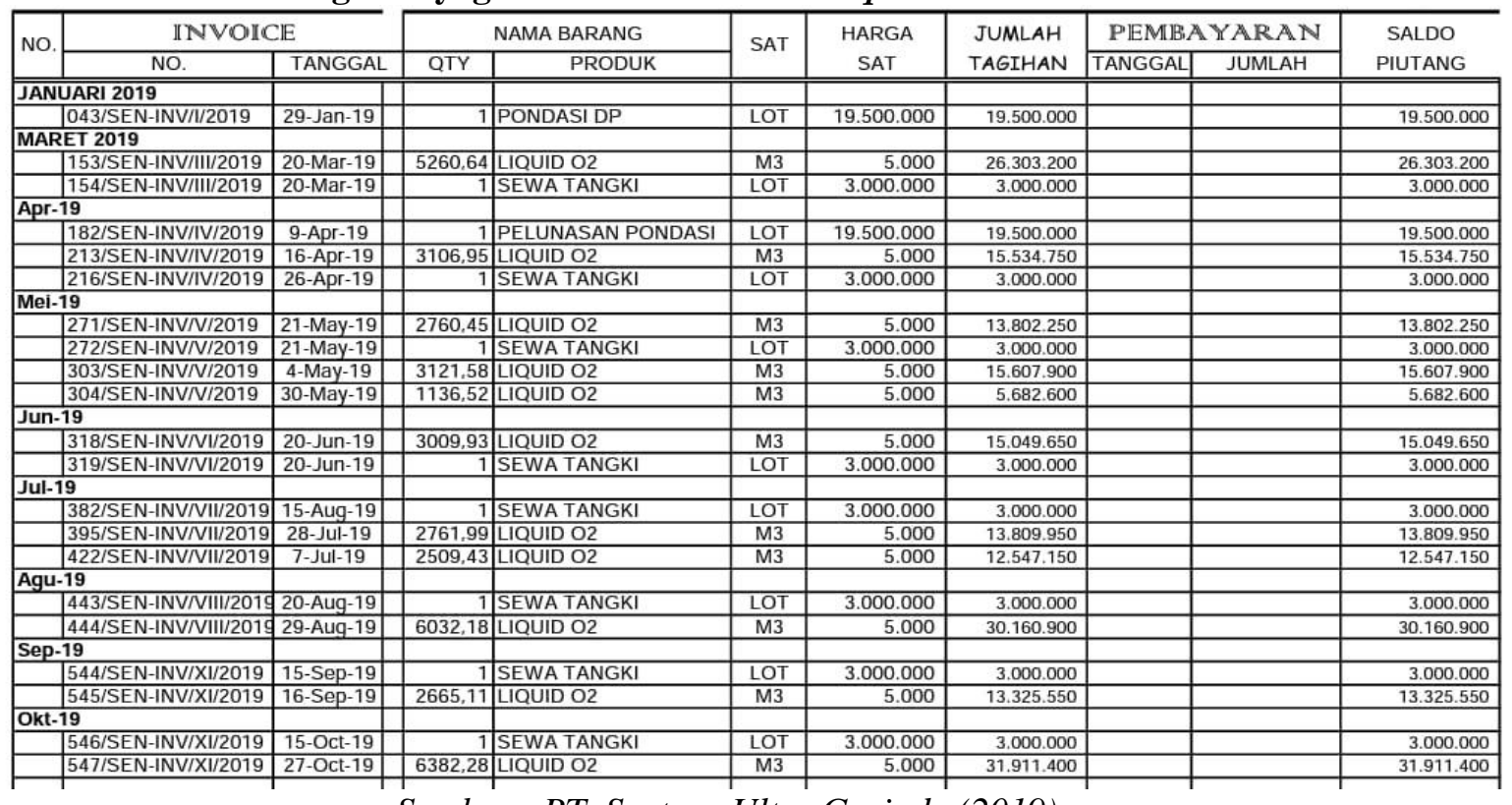

Sumber : PT. Sentosa Ultra Gasindo (2019)

\section{Hasil dan Pembahasan Terkait Input Dalam Penerapan Metode Instalasi Tangki Cryogenic}

Untuk mengetahui bagaimana perbedaan rata-rata jumlah pengiriman oksigen ke Rumah Sakit XYZ oleh PT. Sentosa Ultra Gasindo setiap bulannya, peneliti melakukan wawancara untuk periode sebelum dan sesudah metode intalasi tangki cryiogenic dilakukan.

Sebelum instalasi :

$Q$ : "Berapa kali rata-rata pengiriman pesanan oksigen ke rumah sakit dalam 1 bulan sebelum metode instalasi tangki cryogenic dilakukan?"

A : "Dari informasi yang kami dapat dari pihak rumah sakit, pengiriman oksigen oleh distributor sebelum kami (PT. Sentosa Ultra Gasindo) rata-rata adalah 1 hari sekali setelah pihak rumah sakit melakukan pemesanan. Jadi dalam kurun waktu sebulan lebih kurang hingga 30 kali pengiriman." $(R-1)$

A : "Berdasarkan informasi dari pihak rumah sakit, sekitar 30 kali pengiriman bahkan bisa lebih tergantung dari permintaan rumah sakit." (R-2)

A : "Tidak tahu. Sebab sebelumnya bukan perusahaan kami yang memenuhi permintaan oksigen Rumah Sakit XYZ. (R-4)

Sesudah instalasi :

$Q$; "Berapa kali rata-rata pengiriman pesanan oksigen dari PT. Sentosa Ultra Gasindo ke rumah sakit dalam 1 bulan sesudah metode instalasi tangki cryogenic dilakukan?"

A : "Hanya 2 sampai 3 kali dalam 1 bulan. Tergantung dari jumlah pemakaian oksigen oleh pihak rumah sakit. Sebab yang dikirim bukan dalam bentuk tabung-tabung oksigen melainkan dalam bentuk liquid untuk kemudian diisi ke dalam tangki cryogenic yang sudah diinstal di rumah sakit." (R-1)

A : "Rata-rata 2 hingga 3 kali sebulan dalam bentuk liquid." ( $R-2)$

A : "Sekitar 2 kali dalam 1 bulan. Namun jika pemakaian rumah sakit sedang banyak bisa sampai 3 kali pengiriman." (R-4)

Berdasarkan hasil wawancara dapat disimpulkan bahwa setelah dilakukan instalasi tangki cryogenic di Rumah Sakit XYZ intensitas pengiriman oksigen menjadi jauh lebih sedikit yang sebelumya bisa mencapai 30 kali bahkan lebih dalam sebulan kini menjadi 2 atau 3 kali saja. Jawaban responden tersebut sama dengan hasil telaah dokumen yang didapat dari PT. Sentosa Ultra Gasindo pada Tabel 4.1.

Selanjutnya untuk mengetahui bagaimana perbedaan jumlah biaya pengiriman yang harus dikeluarkan dalam sekali pengiriman dari PT. Sentosa Ultra Gasindo ke Ruah Sakit XYZ, peneliti juga melakukan wawancara dan telaah dokumen.

La Ode Sabaruddin (Penerapan Metode Instalasi Tangki Cryogenic Di Rumah Sakit ...) 
Sebelum instalasi :

Q: "Sebelum dilakukan instalasi tangki cryogenic di rumah sakit, dalam sekali pengiriman oksigen, berapa biaya yang harus dikeluarkan oleh Rumah Sakit dan PT. Sentosa Ultra Gasindo (bensin, tol, sopir, dll)?"

A : "Tidak tahu, sebab bukan kami yang meng-handle hal tersebut. Namun bisa saya perkirakan akan banyak biaya yang timbul dengan melihat intensitas pengiriman yang dilakukan hampir setiap hari." (R-1)

A : "Tidak tahu." (R-4)

Sesudah instalasi :

Q: "Setelah dilakukan instalasi tangki cryogenic di rumah sakit, dalam sekali pengiriman oksigen, berapa biaya yang harus dikeluarkan oleh Rumah Sakit dan PT. Sentosa Ultra Gasindo (bensin, tol, sopir, dll)?"

A : "Untuk detailnya tidak dapat saya pastikan sebab hal tersebut menjadi kewenangan bagian keuangan perusahaan. Namun bisa infokan bahwa harga liquid oxygen dari PT. Air Products sudah termasuk harga franco (sebuah syarat jual beli dimana penjual menanggung biaya pengiriman sampai ke gudang pembeli) rumah sakit." (R-1)

$A$ : "Bisa berbeda-beda tergantung tujuan pengiriman. Namun bisa saya pastikan untuk pengiriman setelah metode instalasi tangki dilakukan akan lebih murah sebab intensitasnya lebih sedikit." (R-4)

Menyimpulkan dari kedua jawaban tersebut dapat terlihat bahwa dengan intensitas pengiriman yang jauh lebih sedikit akan membuat biaya pengiriman lebih murah. Untuk biaya pengiriman setelah stok kebutuhan akan oksigen Rumah Sakit XYZ di-handle oleh PT. Sentosa Ultra Gasindo sudah include dengan harga liquid yang bisa dilihat pada tabel 4.1 kolom JUMLAH TAGIHAN.

\section{Hasil dan Pembahasan Terkait Output Dalam Penerapan Metode Instalasi Tangki Cryogenic}

Berikutnya adalah wawancara untuk mengetahui bagaimana dampaknya dalam hal efektifitas sebelum dan sesudah dilakukan instalasi tangki cryogenic di Rumah Sakit XYZ.

Sebelum instalasi :

$Q$ : "Bagaimana anda melihat perbedaan dalam hal efektifitas untuk rumah sakit sebelum metode intalasi tangki cryogenic diterapkan?"

A : "Ada divisi khusus yang menjaga stok tabung oksigen dan perpindahan tabung oksigen dari gudang ke ruang gas instalasi tangki cryogenic, ada divisi khusus yang menjaga stok tabung oksigen dan perpindahan tabung oksigen dari gudang ke ruang gas." ( $R-1)$

A : "Berdasarkan informasi dari pihak rumah sakit, ada divisi khusus yang menjaga stok persediaan oksigen dan melakukan pemesanan ketika stok oksigen habis atau hampir habis." (R-2)

Sesudah instalasi :

Q: "Bagaimana anda melihat perbedaan dalam hal efektifitas untuk rumah sakit setelah metode intalasi tangki cryogenic diterapkan?"

A : "Tentu saja menjadi lebih efektif sebab hanya perlu sistem pengecekan karena terdapat telemetri di tengki cryogenic. Jika level sudah mencapai $30 \%$ otomatis akan ada indikator order dan segera dikirim." (R-1)

A : "Tidak diiperlukan lagi adanya divisi khusus oleh pihhak rumah sakit untuk menjaga stok persediaan oksigen sebab sudah dapat terindikasi secara otomatis ketika stok tinggal tersisa 30\%." (R-2)

Dari hasil wawancara tersebut dapat disimpulkan bahwa setelah diterapkan metode instalasi tangki cryogenic di rumah sakit, efektifitas dapat terwujud dan memangkas banyak aktifitas-aktifitas yang tidak perlu.

Selanjutnya, untuk mengetahui pengaruh penginstalan tangki cryogenic terhadap efisiensi di Rumah sakit XYZ berikut wawancara peneliti dengan responden.

Sebelum instalasi :

Q: "Bagaimana menurut anda melihat perbedaan dalam hal efisiensi bagi pihak Rumah Sakit sebelum menggunakan metode instalasi tangki cryogenic ini? " 
A : "Menurut kalkulasi saya masih kurang efisien. Informasi yang saya dapat dari pihak rumah sakit, untuk pemakaian tabung oksigen $6 \mathrm{M}^{3}$ bisa mencapai 1200 tabung dalam 1 bulan dimana 1 tabung berisi $6 M^{3}$ liquid oksigen dan harga per tabung Rp. 45.000,-“ (R-1)

$A$ : "Kurang efisien dibandingkan setelah intalasi tangki cryogenic di rumah sakit." $(R-2)$

A : "Tidak tahu, sebab bukan kami yang mensupply oksigen ke rumah sakit. Namun jika melihat dari intensitas pengiriman yang lebih sering tentu akan lebih mahal jika dibandingkan dengan setelah dihandle oleh kami dimana pengiriman hanya 2 sampai 3 kali saja dalam 1 bulan." $(R-4)$

Kemudian untuk melihat perbedaan dalam hal efisiensi setelah penginstalan tangki

cryogenic di rumah sakit berikut wawancaranya.

Setelah instalasi :

$Q$ : "Bagaimana menurut anda melihat perbedaan dalam hal efisiensi bagi pihak rumah sakit setelah menggunakan metode instalasi tangki cryogenic?"

A : "Tentu lebih efisien. Meskipun relatif mahal di awal yang dikarenakan ada biaya pembuatan instalasi tangki cryogenic sebesar RP. 39.000.000,- namun untuk bulan-bulan selanjutnya biaya yang harus dikeluarkan rumah sakit hanya untuk biaya sewa tangki dan pembelian liquid. Jumlah intensitas pengiriman liquid ke rumah sakit juga jauh lebih sedikit sehingga biaya juga menjaadi lebih kecil. Ditambah lagi seperti yang saya infokan sebelumnya bahwa biaya pengiriman liquid tersebut sudahh termasuk ke dalam harga franco rumah sakit.

Saya infokan juga bahwa setelah instalasi selain biaya instalasi tangki cryogenic di awal pemasangan, pada periode-periode berikutnya rumah sakit hanya perlu membayar biaya sewa tangki Rp. 3.000.000,- per bulan dengan harga liquid oksigen Rp. 5000,- per $M^{3}$." $(R-1)$

A : "Jika dikalkulasi secara keseluruhan, mungkin biaya lebih mahal pada awal, namun jika dihitung biaya bulanan yang harus dikeluarkan pihak rumah sakit menjadi lebih murah." (R-2)

Melihat dari jawab responden di atas dapat dihitung berapa estimasi biaya yang harus dikeluarkan rumah sakit setiap bulannya sebelum dan sesudah intalasi tangki cryogenic dilakukan.

Tabel 4.2

Perbedaan Biaya Bagi Rumah Sakit XYZ Sebelum dan Sesudah Instalasi Tangki Cryogenic

\begin{tabular}{|l|l|}
\hline \multicolumn{1}{|c|}{ SEBELUM } & \multicolumn{1}{c|}{ SESUDAH } \\
\hline $\begin{array}{l}\text { Pemakaian tabung oksigen } 6 M^{3}=1200 \\
\text { tabung/bulan }\end{array}$ & $\begin{array}{l}\text { Sewa tangki } \text { cryogenic }=\mathrm{Rp} . \\
3.000 .000 / \text { bulan }\end{array}$ \\
\hline 1 tabung berisi $6 \mathrm{M}^{3}$ liquid oksigen & $\begin{array}{l}\text { Instalasi fondasi dan instalasi jaringan pipa }= \\
\text { Rp. } 39.000 .000\end{array}$ \\
\hline Harga $=45.000 /$ tabung & Harga liquid oksigen $=$ Rp. $5.000 / M^{3}$ \\
\hline
\end{tabular}

Sumber : Hasil Wawancara Penulis terhadap Responden (2019)

Jika dihitung estimasi biaya per bulan yang harus dikeluarkan Rumah Sakit XYZ sebelum instalasi adalah 1.200 tabung x Rp.45.000,- = Rp. 54.000.000,-/bulan. Biaya tersebut hanya untuk biaya pembelian tabung saja dan belum ditambahkan dengan biaya lain-lain termasuk biaya pengiriman.

Sedangkan untuk biaya per bulan yang harus dikeluarkan rumah sakit setelah instalasi tangki cryogenic adalah sewa tangki $=$ Rp. 3.000.000,- ditambah dengan pembelian liquid (sesuai kebutuhan) dimana harga liquid adalah Rp.5000,- $/ M^{3}$.

Harga liquid per $M^{3}$ tersebut lebih murah jika dibandingkan dengan harga per $M^{3}$ liquid sebelum instalasi yaitu Rp. $45.000: 6=$ Rp. 7.500,- per $M^{3}$.

Harga per tabung $6 \mathrm{M}^{3}$ oksigen (sebab dibandingkan dengan sebelum instalasi tangki cryogenic) = Rp. 5.000,- x 6 = Rp. 30.000,-/tabung.

Jika dihitung secara keseluruhan, maka estimasi biaya yang harus dikeluarkan Rumah Sakit XYZ setiap bulan adalah 1.200 tabung x Rp. 30.000,- = Rp. 36.000.000,-/bulan (estimasi pemakaian sama sebelum dan sesudah instalasi). Biaya tersebut sudah termasuk biaya pengiriman.

Selanjutnya peneliti melakukan wawancara untuk melihat bagaimana pengaruh metode instalasi tangki cryogenic terhadap green economic. 
Q: "Bagaimana anda melihat penerapan metode instalasi tangki cryogenic terkait dengan dampaknya terhadap lingkungan?

A : "Menurut saya lebih ramah lingkungan sebab sebelumnya untuk pengiriman dalam bentuk tabung kemasannya menggunakan bejana tekan dalam jumlah banyak. Sementara setelah diterapkan metode instalasi tangki cryogenic storage-nya cukup menggunakan 1 tangki saja.

Zat panas yang dibutuhkan tangki cryogenic juga tidak menggunakan tenaga listrik namun menyerap energi panas yang berasal dari matahari sehingga lebih ramah terhadap lingkungan." ( $R$ 1)

A : "Pengiriman dengan intensitas yang tinggi menyebabkan bahan bakar yang dikonsumsi kendaraan lebih banyak dan hasil pembakarannya tentu akan menyebabkan polusi udara, namun sebaliknya setelah metode instalasi tangki cryogenic dilakukan intensitas pengiriman menjadi jauh lebih sedikit sehingga konsumsi bahan bakar pun secara otomatis ikut berkurang." (R-4)

\section{KESIMPULAN}

1. Berdasarkan hasil penelitian, metode instalasi tangki cryogenic untuk menggantikan cara distribusi oksigen ke rumah sakit yang sebelumnya dikirim dalam bentuk tabung dengan intensitas pengiriman yang tinggi dinilai dapat mewujudkan green logistic sebab dengan semakin sedikitnya intensitas pengiriman yaitu hanya 2 hingga 3 kali dalam 1 bulan maka akan lebih sedikit juga bahan bakar kendaraan yang digunakan untuk pengiriman sehingga lebih ramah terhadap lingkungan.

Perwujudan green economic dan green logistic juga bisa terlihat pada penggunaan tangki storage yang lebih sedikit untuk menggantikan tabung (bejana tekan) yang sebelumnya dibutuhkan dalam jumlah banyak.

Penggunaan energi panas dari matahari menggantikan penggunaan energi listrik untuk pemanasan tangki cryogenic merupakan upaya perusahaan untuk ikut mewujudkan green economic.

2. Dalam hal efisiensi, penerapan metode instalasi tangki cryogenic dinilai lebih efisien dengan estimasi pengeluaran yang dikeluarkan rumah sakit jauh berkurang yang sebelumnya berkisar pada angka Rp. 54.000.000,-/bulan menjadi Rp. 36.000.000,- (denan esimasi pemakaian oksigen sebelum dan sesudah instalasi sama).

3. Dalam hal efektiffitas, penerapan metode instalasi tangki cryogenic dinilai lebih efektif sebab beberapa aktifitas atau divisi di Rumah Sakit XYZ bisa dihilangkan.

\section{DAFTAR PUSTAKA}

Bungkaes, H. R., Posumah, J. H., \& Kiyai, B. 2013. Hubungan Efektivitas Pengelolaan Program Raskin dengan Peningkatan Kesejahteraan Masyarakat di Desa Mamahan Kecapatan Gemeh Kabupaten Kepulauan Talaud. Journal "Acta Diurna"

Hasibuan, S.P. Malayu. 2005. Manajemen Sumber Daya Manusia. Edisi Revisi. Jakarta : Bumi Aksara

Hasibuan, Sayuti. 2000. Manajemen Sumber Daya Manusia : Pendekatan Non Sekuler. Surakarta: Muhammadiyah University Press

Martono, Ricky Virona. 2017. Prinsip Penerapan Green Logistics. [online] Available at < https://swa.co.id/swa/my-article/prinsip-penerapan-green-logistics> [Accessed 28 November 2019]

Masruri. 2014. Analisis Efektifitas Program Nasional Pemberdayaan Masyarakat Mandiri Perkotaan. Padang: Akademia Permata

Moleong, Lexy J. 2012. Metodologi Penelitian Kualitatif. Bandung : PT Remaja Rosdakarya

Nawawi, Hadari. 1997. Manajemen Sumber Daya Manusia Untuk Bisnis Yang Kompetitif. Yogyakarta : Gajah Mada University-Press

Norman K. Denzin. 2009. Handbook of Qualitative Research Edisi Bahasa Indonesia. Yogyakarta : Pustaka Pelajar 
Setiawan, Cecep Isnandar. 2012. Pendinginan Dengan Menggunakan Sistem Kriogenik. [online] Available at $<$ https://www.slideshare.net/cecepisnandarsetiawan/pendinginan-dengan-menggunakan-sistemkriogenik> [Accessed 28 November 2019]

Sugiyono. 2012. Metode Penelitian Kuantitatif, kualitatif dan R \& D. Bandung : Alfabeta

Suyanto, Agus. 2014. Pendinginan dan Pembekuan Hasil Pertanian. [online] Available at $<$ http://tekpan.unimus.ac.id/wp-content/uploads/2014/07/kuliah-teknologi-pendinginan-danpembekuan.ppt $>$ [Accessed 28 November 2019]

UNEP. 2010. Green Economy Report : A Preview.

Wiguna, Candra Aditya. 2014. Tangki Penyimpanan LNG On-Shore. Bontang : LNG Academy 2

Wikipedia. 2019. Green Economy. [online] Availbale at <https://en.wikipedia.org/wiki/Green_economy> [Accessed 28 november 2019]

Yunita, Irma Yoan. 2012. Sistem Kriogenik. [online] Available at <https://id.scribd.com/doc/109268472/Sistem-Kriogenik> [Accessed 28 November 2019] 